\title{
OCORRÊNCIA E PETROGRAFIA DOS METARRIÓLITOS DA FORMAÇÃO NHANGUÇU - GRUPO SERRA DO ITABERABA (SP)
}

\author{
CAETANO JULIANI*, ANNABEL PÉ REZ-AGUILAR**, MARCO A. B. MARTIN ** \& PAULO BELJAVSKIS
}

\begin{abstract}
OCURRENCE AND PETROGRAPHY OF THE METARHYOLITES OF THE NHANGUÇU FORMATION - SERRA DO ITABERABA GROUP (SP) The Nhangucu Formation (Serra do Itaberaba Group) consists mainly ofmanganesiferous metapelites overlain by andalusite schists. Recent geologic mapping showed that this unit also containsfelsic metavolcanics, and the magmatism is therefore bimodal. The contact ofthe metavolcanics with the metapelites is concordant, lacking evidence of contact metamorphism, xenoliths, or other intrusivefeatures. Structural evidence shows that the metavolcanics and metapelites were deformed in the same event, indicating that magmatic event preceded regional metamorphism, therefore being probably syndepositional to the manganesiferous sediments. In handsample the volcanic rocks show abundant relict bipyramidal quartz phenocrystals. In thin section these rocks have a very fine grained matrix made up of muscovite and quartz, containing larger quartz these rocks have a very fine grained matrix made up of muscovite and quartz, containing larger quartz
blastophenocrystals with primary corrosion features. A fine scale schistosity $\left(S_{I}\right)$ is defined by the orientation of muscovite. Thefoliation is tightly folded and cut by a second foliation $\left(S_{2}\right)$ that varies from afine scale axial-plane schistosity to a crenulation cleavage $\left(S_{2}\right)$. The original composition ofthe volcanics was rhyolitic, regisferedfor the first time in the Serra do Itaberaba and São Roque belts.
\end{abstract}

Keywords: Metarhyolite, bipyramidal quartz phenocrystal, Nhanguçu Formation, Serra do Itaberaba Group.

RESUMO A Formação Nhanguçu (Grupo Serra do Itaberaba) é composta predominantemente por metapelitos manganesíferos capeados por xistos com andalusita. Mapeamento recente mostrou que a unidade também contém rochas metavulcânicas ácidas, caracterizando a existência de magmatismo bimodal no grupo.

As estruturas expostas em afloramentos indicam que estas rochas tiveram origem efusiva, pois não há evidência de metamorfismo de contato, xenólitos e outras feições intrusivas nos metapelitos encaixantes. As estruturas tectônicas mostram que ambos litotipos foram afetados pêlos mesmos eventos deformacionais.

Ao microscópio, as metavulcânicas são muito finas e apresentam relíquias de fenocristais bipirarnidais de quartzo, com faces corroídas e bolsões preenchidos pela matriz, típicos de riólitos.

A matriz é composta por muscovita e quartzo e a orientação da mica define uma xistosidade fina que encontra-se deformada por dobras fechadas, com recristalização segundo uma foliação plano-axial que varia entre xistosidade fina e superfície de crenulacão. Estas estruturas são correlacionáveis às registradas nos metapelitos manganesíferos e correspondem às foliacões regionais $\mathrm{S}_{1} \mathrm{e} \mathrm{S}_{2}$, que, em conjunto com as relações de contato com as encaixantes, indicam que a atividade ígnea foi concomitante à sedimentação.

Palavras-chave: metarriólitos, fenocristais bipiramidados de quartzo, Formação Nhanguçu, Grupo Serrado Itaberaba

INTRODUÇÃO O Grupo Serra do Itaberada (Juliani et al. 1986), localiza-se à nordeste da cidade de São Paulo (Fig. 1) e subdivide-se na Formação Morro da Pedra Preta, de natureza vulcano-sedimentar e estratigraficamente sotoposta à Formação Nhanguçu, composta por metassedimentos pelíticos ricos em ferro e manganês e clorita-muscovita xistos com porfiroblastos de andalusita, e na Formação Pirucaia, representada por quartzitos e quartzo xistos, que corresponde a variações faciológicas das formações anteriores, especialmente da Formação Nhanguçu.

Na Formação Morro da Pedra Preta Juliani et al. (1986) e Juliani (1993) descrevem corpos restritos de rochas metavulcânicas/subvulcânicas andesíticas a dacíticas com frequentes relíquias de texturas ígneas e vulcanoclásticas. Os metarriólitos foram considerados como muito raros e, devido às transformações metamórficas que destruíram as texturas ígneas, somente puderam ser caracterizados pelo seu modo de ocorrência e composição química (Juliani 1993). Entretanto, durante pesquisas recentes na região foi registrada a primeira ocorrência de rochas félsicas com texturas ígneas preservadas e relações de contato que permitiram caracterizá-las como metarriólitos.

Estas rochas estão encaixadas em metapelitos manganesíferos da base da Formação Nhanguçu, que corresponde à sequência superior do Grupo Serra do Itaberaba (Juliani 1993, Juliani et al. 1994, Juliani \& Beljavskis 1995). Os metarriólitos localizam-se na estrada municipal GuarulhosSanta Isabel, após a entrada da Fazenda Vitale, a sudeste da Indústria de Bebidas Skol (ocorrência A, Fig. 1).
Após os estudos de campo e petrográficos desta primeira ocorrência, novos afloramentos de metarriólitos (ocorrências B, Fig. 2) foram encontrados na Formação Morro da Pedra Preta. Estes são mais foliados e recristalizados, e se associam a marunditos (margarita-coríndon xistos) descritos por Juliani (1993) e Martin \& Juliani (1994).

CONTEXTO GEOLÓGICO Segundo Juliani et. ai. (1994) e Juliani \& Beljavskis (1995), o Grupo Serra do Itaberaba se subdivide nas formações Morro da Pedra Preta, Nhanguçu e Pirucaia.

A Formação Morro da Pedra Preta é a unidade basal, composta predominantemente por anfibolitos, anfibólio xistos, metabasitos e metapelitos. Subordinadamente, a unidade contém rochas metavulcanoclásticas intermediárias a ácidas, calciossilicáticas, metassedimentares quartzosas, formações ferríferas, metacherts, granada-cordierita-cummingtonita anfibolitos, turmalinitos e margarita-coríndon xistos. As rochas metabásicas localmente possuem relíquias de tipo pillow. A composição química das metavulcânicas básicas é compatível com tholeiítos Tipo $\mathrm{N}$ de cadeias meso-oceânicas com gradações para o Tipo E (Juliani, 1993).

A Formação Nhanguçu está concordantemente superposta à anterior, mas com discordâncias erosivas e/ou tectônicas locais. A unidade é constituída por metapelitos manganesíferos e metacalciopelitos, raros metabasitos, metavulcanoclásticas e turmalinitos e, no topo, lentes subordinadas de mármores e rochas calciossilicáticas. Este conjunto está recoberto por xistos finos bandados, ricos em andalusita. Com o presente trabalho, a unidade passa a conter também metarriólitos.

*Patrocínio da FAPESP, proc. 93/4350-0 e apoio do CNPq (bolsas de IC e mestrado).

Departamento de Mineralogia e Petrologia, Instituto de Geociências, Universidade de São Paulo, Caixa Postal 11348, CEP 05422-970, São Paulo, SP, Brasil, Fax (55-011) 818 4258, Fone (55-011) 818 3998. E-mail: cjuliani@usp.br

**Pós-graduandos do Departamento de Mineralogia e Petrologia, Instituto de Geociências, Universidade de São Paulo, Caixa Postal 11348, CEP 05422-970, São Paulo, SP, Brasil, Fax (55-011) 818 4258, Fone (55-011) 818 4023. E-mail: aperez@usp.br, martin@usp.br

***Pós-graduando do Departamento de Geologia Económica, Instituto de Geociências, Universidade de São Paulo, Caixa Postal 11348, CEP 05422-970, São Paulo, SP, Brasil, Fax (55-011) 818 4207, Fone (55-011) 8184144. 


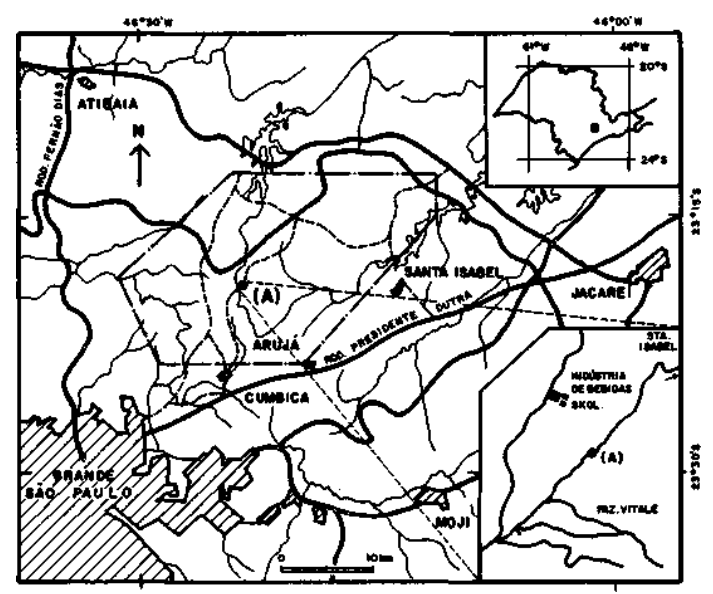

Figura 1 - Localização da área e da ocorrência pesquisada (A). Figure 1 - Location of the área and the researched occurrence $(\mathrm{A})$.

A Formação Pirucaia consiste de quartzitos e quartzo xistos derivados de rochas sedimentares elásticas grossas das partes marginais da bacia deposicional do Grupo Serra do Itaberaba.

O Grupo São Roque, representado pelas rochas da Formação Piragibu, conforme a redefinição de Juliani (1993), Juliani et al. (1994) e Juliani \& Beljavskis (1995), recobre as rochas do Grupo Serra do Itaberaba por falhas de empurrão e também, possivelmente, através de discordâncias erosivas.

$\mathrm{O}$ conjunto está coitado por granitos, granodioritos e tonalitos, porfiríticos ou não, e zonas de cisalhamento transcorrentes recorrentes.
CARACTERÍSTICAS DOS METARRIÓLITOS

Feições de Campo Três corpos de metarríólitos (ocorrência A, Fig. 2) afloram em uma extensão de cerca de $100 \mathrm{~m}$, dispostos concordantemente aos metapelitos manganesíferos da Formação Nhanguçu. Os três corpos, de norte para sul, têm espessuras aproximadas de, respectivamente, 2, 1,5 e $2 \mathrm{~m} \mathrm{e}$ estão, em geral, intemperizados para material branco amarelado a ocre, argiloso, rico em sericita e pequenos grãos e agregados de quartzo. Delgados veios de quartzo deformados, pré-metamórficos, também estão presentes. Apenas um dos corpos contém porções inalteradas e que permitem estudos petrográficos.

Os metapelitos manganesíferos encaixantes também estão intemperizados e são cinza claros acastanhados ou esverdeados. Estas rochas são bandadas onde leitos quartzosericíticos alternam-se com leitos escuros ou pretos ricos em óxidos e hidróxidos de ferro e manganês, que também preenchem fraturas. As porções manganesíferas mais espessas e alteradas possuem cor de pó de café.

Ao microscópio, os metapelitos manganesíferos apresentam muscovita, quartzo, biotita e minerais opacos e, localmente, epidoto, tremolita e diopsídio.

Os contatos dos metarriólitos com os metapelitos manganesíferos estão bem expostos em dois dos corpos e são concordantes com o bandamento composicional dos metapelitos. Localmente os dois litotipos são subconcordantes, notadamente na porção norte do terceiro corpo, onde a transposição $\left(\mathrm{S}_{2}\right)$ desmembrou e estirou os metarriólitos em lentes de 1 a 3 $\mathrm{cm}$ de espessura, incluindo-as na rocha encaixante.

Os metarriólitos apresentam uma foliação metamórfica que orienta, estira e rotaciona grãos e agregados de quartzo. Especialmente no primeiro corpo, situado a norte, estes grãos

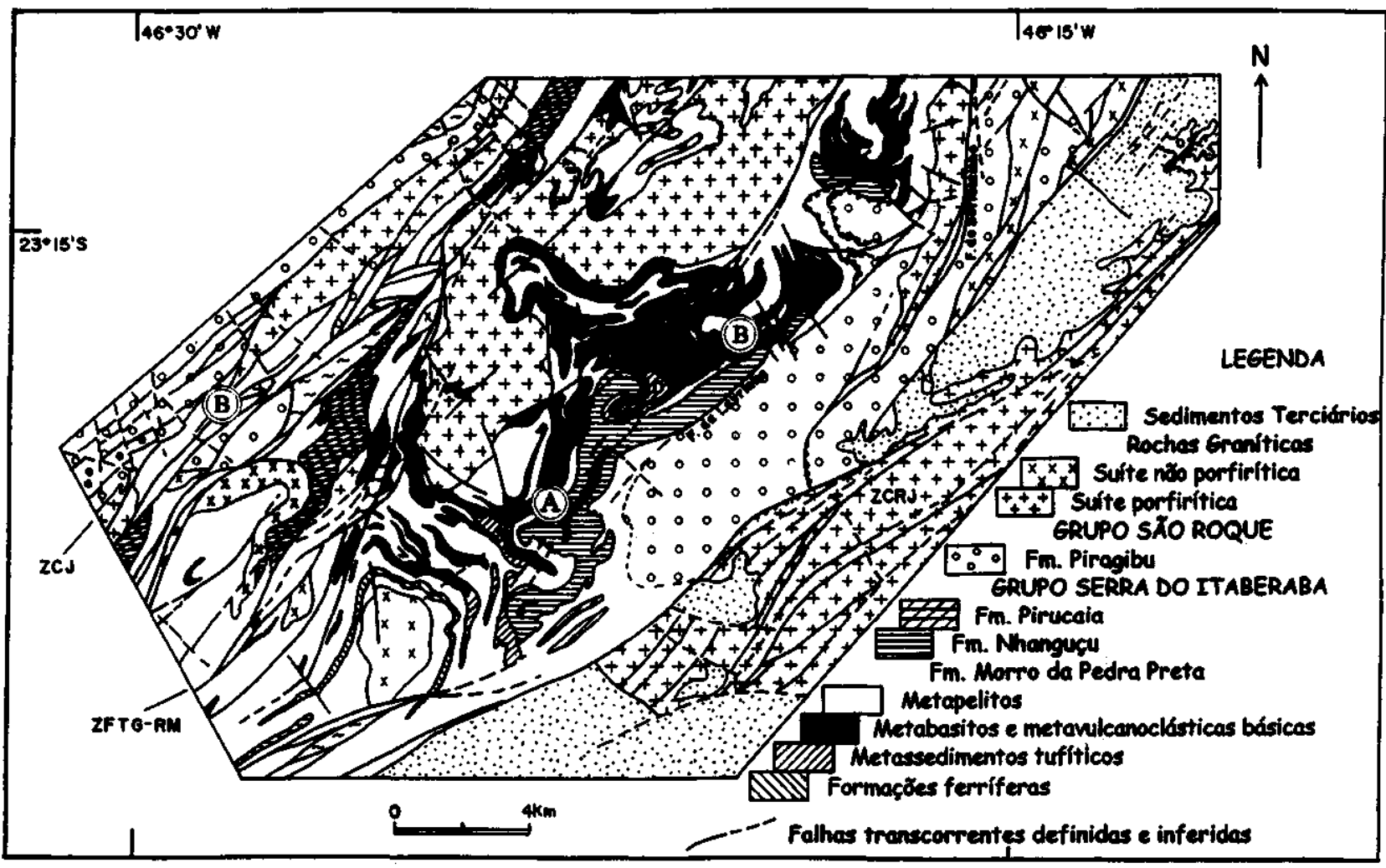

Figura 2 - Contexto geológico regional, com a localização da ocorrência dos três corpos de metarriólitos estudados (A) e das posteriormente encontradas (B). Modificado de Juliani et. al (1994), onde ZCJ=Zona de Cisalhamento Jundiuvira, ZCRJ = Zona de Cisalhamento do Rio Jaguari e ZFTG-RM = Zona de Falhas do Tanque Grande - Ribeirão dos Macacos.

Figure 2 - Regional geologic context, with the localization of the occurrence of the three bodies of metarhyolites studied (A) and those found alterwards (B). Modified from Juliani et al. (1994), where ZCJ = Jundiuvira shear zone, ZCRJ = Rio Jaguari shear zone and ZFTG-RM = Tanque Grande -Rio dos Macacos fault zone. 
atingem até $4 \mathrm{~mm}$ de diâmetro e ainda apresentam o hábito bipiramidal característico de metarriólitos (Figs. 3 e 4).

Dobras intrafoliais $\mathrm{D}_{2}$ com superfície plano-axial $\left(\mathrm{S}_{2}\right)$ subparalela à $\mathrm{Só} / \mathrm{Si}$ são frequentes no metapelito manganesífero próximo aos metarriólitos. Uma xistosidade fina $\left(\mathrm{S}_{3}\right)$, que localmente grada para uma clivagem de crenulação, superpõese às estruturas $\mathrm{D}_{2}$. Estas mesmas estruturas afetam as metavulcânicas, mas devido a sua menor competência, as $\mathrm{S}_{2}$ e $\mathrm{S}_{3}$ não estão bem desenvolvidas, melhor preservando a Si. Os fragmentos tectônicos de metarriólitos estirados em lentes relacionam-se a domínios estruturais onde a $\mathrm{S}_{2}$ é mais densa, devido à deformação mais intensa.

Não foram observadas feições intrusivas, tais como metamorfismo de contato, apófises, veios, contatos discordantes com a encaixante e xenólitos. Também não foram reconhecidas estruturas vulcanoclásticas. Os veios de quartzo deformados cortam apenas as metavulcânicas, sugerindo terem se formado ao final da cristalização magmática.

As evidências mesoscópicas indicam que estas metavulcânicas foram posicionadas previamente ao evento metamórfico/deformacional.

Petrografia Ao microscópio, os metarriólitos exibem como "feições de compo" textura porfirítica reliquiar, com fenocristais de quartzo bipiramidados parcialmente recristalizados em uma matriz muito fina ( $\sim 0,04 \mathrm{~mm}$ em moda), composta por quartzo (30 a $35 \%$ ), muscovita (60 a $65 \%$ ) e traços de diminutos cristais de zircão, turmalina e opacos.

Apresentam duas foliações proeminentes, sendo a mais antiga uma xistosidade fina amoldada aos agregados e fenocristais de quartzo (Fig. 5), ou a agregados de muscovita, geralmente rotacionados e com sombras de pressão. Esta foliação não contém relíquias de foliações metamórficas anteriores e afeta as texturas ígneas, permitindo interpretá-la como a $\mathrm{Si}$. A superfície $\mathrm{S}_{2}$ é plano-axial a dobras fechadas e reorienta a muscovita e o quartzo cristalizados na $\mathrm{S}$ i com total transposição local. Também ocorre uma $\mathrm{S}_{3}$, menos evidente, que recristaliza e reorienta a muscovita. A granulação da mica é mais grossa na $\mathrm{S}_{2}$ e em alguns porfiroblastos pós-S $\mathrm{S}_{3}$.

Estas rochas frequentemente mostram uma discreta laminação dada pela alternância de leitos mais ricos em quartzo ou muscovita, interpretada como primária, por fluxo ígneo ou vulcanoclástico, mas não ocorrem texturas vulcanoclásticas típicas. As estruturas tectônicas e as texturas dos minerais metamórficos não indicam ser um bandamento metamórfico.

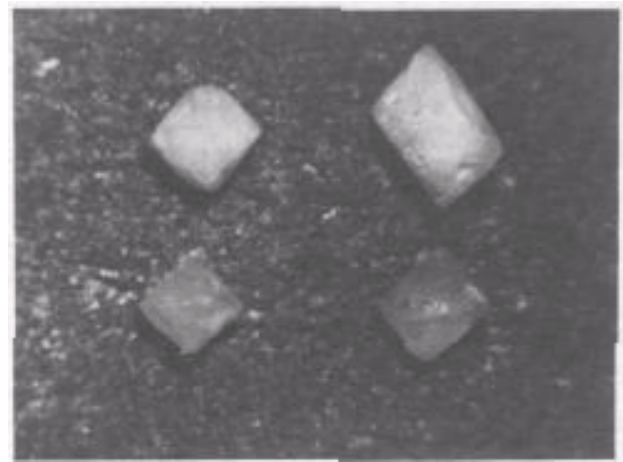

Figura 3 - F otomicro grafia (estereomicroscópica) mostrando o aspecto dos cristais bipiramidais de quartzo da Formação Nhanguçu. O cristal situado a nordeste apresenta faces bastante corroidas. O cristal maior apresenta $3 \mathrm{~mm}$ de comprimento.

Figure 3 - Photomicrograph (stereomicroscopic) showing the aspect of bipyramidal quartz crystals of the Nhanguçu Formation. The northeastern crystal presents highly corroded faces. The length of the largest crystal is 3.0 mm.

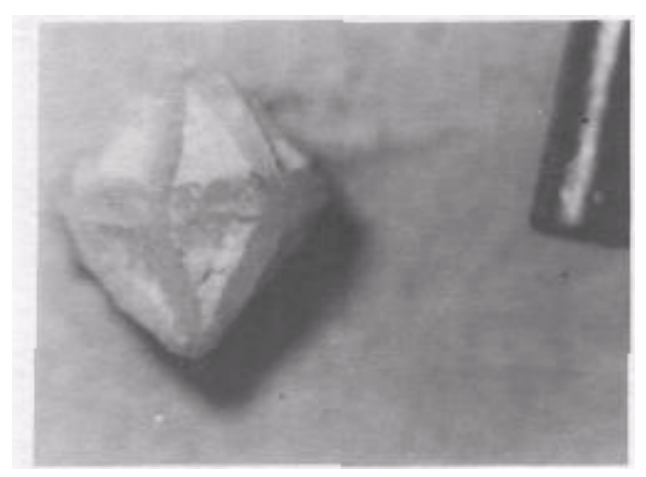

Figura 4 - F otomicro gr afia (estereomicroscópica) de um cristal bipiramidal de quartzo com as faces corroídas. A escala é dada pela ponta da lapiseira $(0,5 \mathrm{~mm})$ no lado direiro da figura. Figure 4 - Photomicrograph (stereomicroscópio) of bipyramidal quartz crystal with faces corroded. The scale is given by the tip of the pencil $(0.5 \mathrm{~mm})$ at the right-hand side of the figure.

Veios de quartzo recristalizados, com espessura milimétrica, cortam a rocha em lâmina delgada, de forma análoga ao verificado nos afloramentos.

Os fenocristais de quartzo perfazem cerca de $2-5 \%$ da rocha e têm entre 1 e 1,25 mm, esporadicamente $4 \mathrm{~mm}$ de diâmetro. Em sua maioria são bipiramidais subeuédricos a euédricos, geralmente com feições de corrosão magmática nas bordas, e cavidades e bolsões preenchidos pela matriz (Fig. 6), semelhantes às descritas por Mackenzie et. al. (1982) e Williams et al. (1982). Os fenocristais têm, frequentemente, inclusões de muscovita e outros minerais de granulação muito fina, de difícil identificação, mas alguns parecem ser zircão e apatita. Os fenocristais apresentam extinção ondulante; às vezes estão recristalizados para agregados de subgrãos de textura granoblástica. Também apresentam-se em agregados, representando texturas glomeroporfiríticas originais. $\mathrm{O}$ quartzo da matriz é fino, tem contornos irregulares, extinção ondulante e, frequentemente, contém inclusões de muscovita.

Agregados de finos cristais de quartzo anedrais com secções circulares ou alongadas ( $\sim 1 \mathrm{~mm}$ de comprimento), às vezes com ténue zonamento concêntrico, sugerem amígdalas ou vesículas recristalizadas (Fig. 7).

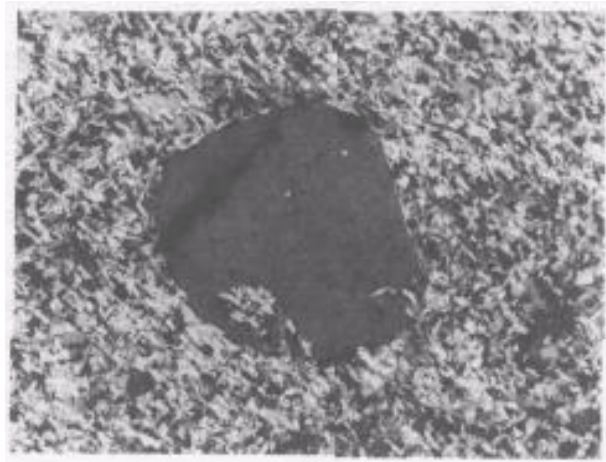

Figura 5 - Fotomicrografia de fenocristal de quartzo (2 $\mathrm{mm})$ com faces corroídas e bolsão de matriz de quartzo e muscovita. Os minerais da matriz orientados na direção noroeste-sudeste, delineiam a $S_{1}$, mais densa, e os orientados segundo nordeste-sudoeste são da $S_{2}$. Analisador cruzado. Figure 5 - Photomicrograph of the quartz phenocrystal $(2.0 \mathrm{~mm})$ with corroded faces containing also quartz and muscovite of the matrix. The matrix minerais oriented in the northwest-southeast direction represent the S 1 schistosity and those oriented northeast-southwest the S2. Crossed nicols. 


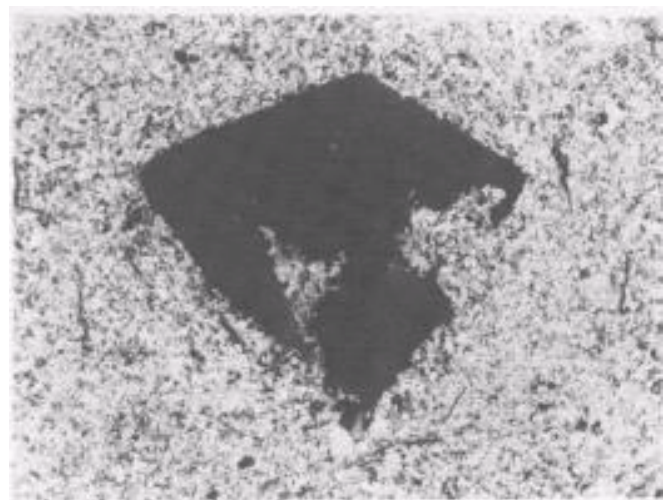
deformado. Lado maior da figura $(2 \mathrm{~mm})$. Analisador cruzado. Figure 6 - Photomicrography of a corroded and deformed phenocrystal. Large side of the figure $(2.0 \mathrm{~mm})$. Crossed nicols.

Em porções menos deformadas da matriz ocorrem agregados de muscovita correspondendo, possivelmente, a relíquias de textura glomeroporfirítica de feldspato potássico.

$\mathrm{O}$ zircão ocorre na matriz com granulação muito fina ou incluso nos fenocristais de quartzo e traços de opacos estão presentes.

Não foram observadas relíquias de feldspato potássico, devido à sua transformação para muscovita, ou de plagioclásio, cujo teor na rocha original deve ter sido pequeno, pois não há presença de minerais metamórficos sugestivos, como epidoto ou carbonato. Também não foram observados encraves dos metapelitos encaixantes ou xenocristais de quartzo.

Mesmo na ausência de feldspatos ígneos, ainda que reliquiares, que poderiam proporcionar uma classificação mais segura do protólito, o predomínio de muscovita e o teor de quartzo da matriz permitem interpretar a composição original como riolítica.

DISCUSSÃO A análise estratigráfica e química da sequência vulcano-sedimentar do Grupo Serra do Itaberaba indica, segundo Juliani (1993), que sua evolução iniciou com a deposição em um rift ensiálico que evoluiu para uma bacia oceânica profunda, quando, então, o maior volume das rochas básicas foi formado em ambiente de MORB e capeadas por sedimentos pelágicos e químicos. A continuidade da sedimentação deu-se em uma bacia de retro-arco, com a deposição da Formação Nhanguçu em águas gradativamente mais rasas e com menor atividade vulcânica e exalativa.
Figura 6 - Fotomicrografia de um fenocristal corroído e

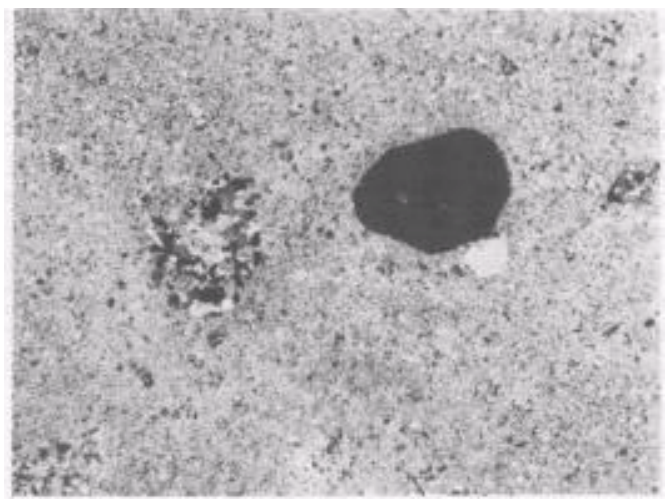

Figura 7 - Fotomicrografia de fenocristais de quartzo ao lado de um agregado policristalino de quartzo recristalizado (l $\mathrm{mm}$ ), representando possíveis relíquias de amígdalas. Analisador cruzado.

Figure 7 - Photomicrograph of quartz phenocrystals with a neighbouring policrystalized aggregate of recrystallized quartz $(1.0 \mathrm{~mm})$ representing a possible relict amygdale. Crossed nicols.

Os metandesitos, metarriodacitos e metaríolitos que ocorrem principalmente no topo da Formação Morro da Pedra Preta têm afinidade tholeiítica, com gradações para cálcio-alcalina e foram, provavelmente, gerados por fusão de crosta oceânica durante a subducção. Neste contexto os metarriólitos da Formação Nhanguçu corresponderiam aos termos vulcânicos mais diferenciados da evolução magmática do Grupo Serra do Itaberaba.

A datação destes metarriólitos é fundamental pois, além de contribuir para o entendimento da evolução geológica dos grupos Serra do Itaberaba e São Roque, definirá o hiato deposicional entre ambos. Na região existe apenas a datação dos metarriodacitos do Morro do Polvilho, a noroeste da cidade de São Paulo (Van Schmus et al 1986), encaixados na base do Grupo São Roque (Carneiro 1983, Carneiro et al. 1984), que forneceram idade U-Pb de $1,79 \mathrm{Ga}$, utilizada como indicativa para uma evolução de ambos os grupos no Proterozóico Médio/Superior.

Agradecimentos Os autores agradecem aos revisores anónimos e ao Prof. Dr. Hardy Jost pelas críticas e sugestões ao texto, à FAPESP (Proc. 93/4350-0) pelo apoio financeiro e ao CNPq pela concessão das bolsas de Iniciação Científica a Marco Aurélio Bonfá Martin (Processo 800549/93-7) e de Mestrado a Annabel Pérez-Aguilar (IGUSP / 1991 a 1993).

\section{REFERÊNCIAS}

CARNEIRO, C. D. R. 1983. Análise estrutural do Grupo São Roque na faixa entre o Pico do Jaraguá e a Serra dos Cristais, SP. São Paulo, 155p. (Tese de Doutorado, Instituto de Geociências da Universidade de São Paulo).

CARNEIRO, C. D. R.; COUTINHO, J. M. V.; SUEMITSU, A.; RODRIGUES, E. de P. 1984. Relações geométricas e temporais de eventos magmáticos no Grupo São Roque a partir da descoberta de rochas metavulcânicas e da apli-cação de critérios estruturais. In: CONGRESSO BRASILEIRO DE GEOLOGIA, 33, Rio de Janeiro, 1984. Anais..., Rio de Janeiro, SBG, v.7, p. $3196-3211$.

JULIANI, C. 1993. Geologia, petrogênese e aspectos metalogenéticox do grupos Serra do Itaberaba e São Roque na região das serras do Itaberaba e da Pedra Branca, NE da cidade de São Paulo. São Paulo, 803p. (Tese de Doutorado, Instituto de Geociências da Universidade de São Paulo).

JULIANI, C. \& BELJAVSKIS, P. 1995. Revisão da litoestratigrafia da faixa São Roque/Serra do Itaberaba (SP). Revista do Instituto Geológico. 16(1/2):33-58

JULIANI, C.; BELJAVSKIS, P.; SCHORSCHER, H.D. 1986. Petrogênese do vulcanismo e aspectos metalogenéticos associados: Grupo Serra do Itaberaba na região do São Roque - SP. In: CONGRESSO BRASILEIRO DE GEOLOGIA, 34, Goiânia, 1986. Anais..., Goiânia, SBG, v.2, p. 730-743.
JULIANI, C; SCHORSCHER, H.D ; BELJAVSKIS, P · GARDA, G.M. 1994. Lito-estratigrafia e petrografia do Grupo Serra do Itaberaba, NE da cidade de São Paulo. In: CONGRESSO BRASILEIRO DE GEOLOGIA, 38, Balneário de Camburiú, 1994. Boletim de Resumos Expandidos..., Balneário de Camburiú, SBG, v.2, p. 101-103.

MACKENZIE, W.S.; DONALDSON, C.H.; GUILFORD, C. 1982. Atlas of igneous rocks and their textures. Harlow: Longman. 148 p.

MARTIN, M.A.B. \& JULIANI, C. 1994. Geologia, petrografia e génese dos marunditos (margarita-corindon xistos). In: CONGRESSO BRASILEIRO DE GEOLOGIA, 38, Balneário de Camburiú, 1994. Boletim de Resumos Expandidos.... Balneário de Camburiú, SBG, v.3, p. 77-78.

VAN SCHUMUS, W.R.; TASSINARI, C.C.G.; CORDANI, U.G. 1986. Estudo geocronológico da parte inferior do Grupo São Roque. In: CONGRESSO BRASILEIRO DE GEOLOGIA, 34, Goiânia, 1986.Anais..., Goiânia, SBG, v. 3, p. 1399-1406

WILLIAMS, H.; TURNER, F.J.; GILBERT, C.M. 1982. Petwgraphy - An introduction to study of rocks in thin sections. 2 ed. New York: W. J. Freeman. 626p.

Manuscrito NB011

Recebido em 16 de agosto de 1996

Revisão dos autores em 16 de outubro de 1996 Revisão aceita em 18 de outubro de 1996 